Article

\title{
Heliocephala variabilis and Pseudopenidiella vietnamensis: Two New Hyphomycetous Species in the Microthyriaceae (Dothideomycetes) from Vietnam
}

\author{
Isabel Iturrieta-González ${ }^{\circledR}$, Dania García *®D , Josep Guarro and Josepa Gené \\ Unitat de Micologia, Facultat de Medicina i Ciències de la Salut and IISPV, Universitat Rovira i Virgili, Reus, \\ 43201 Tarragona, Spain; isabeliturrieta@gmail.com (I.I.-G.); josep.guarro@urv.cat (J.G.); josepa.gene@urv.cat (J.G.) \\ * Correspondence: dania.garcias@urv.cat; Tel.: + 34-673735073
}

Received: 29 February 2020; Accepted: 26 March 2020; Published: 27 March 2020

\begin{abstract}
In a survey of microfungi from plant debris collected in Vietnam, two new hyphomycetous species were found, which belong to the genera Heliocephala and Pseudopenidiella and the family Microthyriaceae (Microthyriales, Dothideomycetes). Maximum Likelihood and Bayesian Inference sequence analyses of the internal transcribed spacers (ITS) and large subunit (LSU) of the ribosomal DNA barcodes allowed assessing the phylogenetic relationships of the new species with other species of the respective genera. Heliocephala variabilis sp. nov. was closely related to Heliocephala elegans, Heliocephala gracilis, and Heliocephala zimbabweensis, from which it was morphologically distinguished by its smaller conidiophores and non-rostrate conidia of up to four septa on the natural substratum. Pseudopenidiella vietnamensis sp. nov. was related to Pseudopenidiella piceae and Pseudopenidiella podocarpi and differed from the former principally by its lack of microcondiophores and from P. podocarpi by having larger macroconidiophores and smooth conidia. Key morphological features to distinguish the accepted species in Heliocephala and Pseudopenidiella are also provided. In addition, Pseudopenidiella pini was excluded from the genus on the basis of its morphological features.
\end{abstract}

Keywords: hyphomycetes; dematiaceous fungi; phylogeny; taxonomy; Vietnam

\section{Introduction}

Vietnam is one of the twenty most bio-diverse countries in the world [1-3]. Its very diverse ecological niches, climatic conditions, and high level of plant endemism would suggest that the country also has great fungal diversity, although this has been not extensively studied so far [4-6]. During a survey of asexual microfungi from plant debris carried out in the Northeast of Vietnam, two interesting specimens, belonging to the genera Heliocephala and Pseudopenidiella (Microthyriaceae, Microthyriales, Dothideomycetes) [7] were isolated and deposited in the culture collection at the Medicine Faculty of the Universitat Rovira i Virgili (Reus, Spain) for subsequent studies.

The genus Heliocephala was introduced by Rao et al. [8] based on Heliocephala proliferans, a hyphomycetous fungus characterized by the production of solitary macronematous conidiophores, bearing a terminal compact clusters of monoblastic conidiogenous cells that can arise more or less radially from short branches (metula-like) and produce obclavate, rostrate, or hooked conidia. Based on DNA data and morphological features, the genus was emended by Heredia-Abarca et al. [9] to include the species of Holubovaniella [10], the latter subsequently being considered a synonym of Heliocephala. Currently, Heliocephala comprises seven species, most of them isolated from plant material, with the exception of Heliocephala natarajanii, which was found along with a basidiocarp of Pisolithus tinctorius [11].

Crous et al. [12] introduced the genus Pseudopenidiella to accommodate Pseudopenidiella piceae recovered from the needle litter of Picea abies in the Czech Republic. Morphologically, the genus is 
characterized by the presence of micro- and macroconidiophores, with aseptate conidia and ramoconidia arranged in branched acropetal chains. It shows a conidiogenous apparatus similar to those of the genera Cladosporium, Digitopodium, and Penidiella, but mainly differs from them by the lack of darkened and coronate-type scars in both conidia and conidiogenous cells and by the absence of rhizoids associated with the conidiophores. Phylogenetically, three species have been recognized in the genus, Pseudopenidiella podocarpi being the most recently described on leaves of Podocarpus latifolus, collected in South Africa [13].

Based on a polyphasic approach, we propose two novel hyphomycetous fungi from Vietnam, Heliocephala variabilis and Pseudopenidiella vietnamensis, which are described and illustrated below.

\section{Material and Methods}

\subsection{Samples and Isolates}

Samples of plant debris were collected in the Northeast region of Vietnam in 2011 and treated according to Hernández-Restrepo et al. [14]. They were placed in moist chambers and incubated at room temperature $\left(22^{\circ} \mathrm{C}\right)$ in darkness, being examined periodically under a stereomicroscope over a 3-month period. The fungi were isolated on potato dextrose agar (PDA; Pronadisa, Madrid, Spain), and the interesting specimens were preserved at room temperature on PDA slant cultures covered with mineral oil.

\subsection{DNA Extraction, PCR, Sequencing and Phylogenetic Analyses}

Isolates were grown on PDA for 14 days at $25^{\circ} \mathrm{C}$ in darkness, and DNA was extracted from mycelium through the modified protocol of Müller et al. [15]. For identification purposes, we performed the PCR using the primer pairs ITS5/ITS4 and NL1/NL4b to amplify the region spanning the internal transcribed spacers (ITS) 1 and 2, including the 5.8S gene, and the D1/D2 domain of the large subunit (LSU) of the nuclear ribosomal (nr)DNA, respectively, following the protocol of Cano et al. [16]. The PCR products were purified and stored at $-20^{\circ} \mathrm{C}$ until sequencing at Macrogen (Madrid, Spain).

ITS and LSU sequences of the unidentified isolates were compared with those of other fungi deposited at the National Center for Biotechnology Information (NCBI) by the Basic Local Alignment Search Tool (BLAST). To assess the taxonomic position and phylogenetic relationships of our fungi, we carried out single analyses of the ITS and LSU sequences obtained here and those available of Heliocephala and Pseudopenidiella species and other members of the family Microthyriaceae. Since a similar topology of the phylogenetic trees obtained from the previous analyses was observed, a combined analysis of the two markers was performed to obtain a more robust phylogeny of the fungi studied. All the sequences, which were mainly taken from previous studies $[7,9,12,13,17-20]$, were retrieved from GenBank, including those of Venturia catenospora and Venturia inaequalis used as outgroup (Table 1). The alignments were made in the MEGA (Molecular Evolutionary Genetics Analysis) software v.6.0. [21], using the ClustalW algorithm [22] and refined with MUSCLE [23] or manually if necessary, on the same platform. Phylogenetic reconstructions were made using Maximum Likelihood (ML) and Bayesian Inference (BI) approaches using the MEGA software v. 6.0. [21] and MrBayes v. 3.2.6 [24], respectively.

For the ML analysis of the ITS and LSU regions, the best nucleotide substitution model determined by the same program was the Tamura-Nei model with Gamma distribution and invariant sites (T93+G+I); ML bootstrap values (BML) $\geq 70 \%$ were considered significant. For the BI analysis, the best nucleotide substitution model was determined using jModelTest [25]. For the ITS region, we used the Kimura 2-parameter with Gamma distribution $(\mathrm{K} 80+\mathrm{G})$ and for the LSU region, we used General Time Reversible with Gamma distribution and invariant sites $(G T R+G+I)$. The parameters used were two simultaneous runs of 5,000,000 generations, four Markov chains, sampled every 1000 generations. The 50\% majority-rule consensus tree and posterior probability values (PP) were calculated after discarding the first $25 \%$ of the samples. A PP value $\geq 0.95$ was considered significant. 
Table 1. Species included in this study, their substrate, origin, and GenBank accession numbers.

\begin{tabular}{|c|c|c|c|c|c|}
\hline \multirow{2}{*}{ Species } & \multirow{2}{*}{ Strain Number ${ }^{1}$} & \multirow{2}{*}{ Substrate } & \multirow{2}{*}{ Country } & \multicolumn{2}{|c|}{ Genbank Accession No. ${ }^{2}$} \\
\hline & & & & ITS & LSU \\
\hline Chaetothyriothecium elegans & CPC $21375^{\mathrm{T}}$ & Leaves of Castanopsis sp. & Thailand & - & KF268420 \\
\hline Heliocephala elegans & MUCL 39003 & Fallen leaf of Andira inermis & Cuba & HQ333478 & HQ333478 \\
\hline H. gracilis & CBS $369.86^{\mathrm{IT}}$ & Fallen leaf of Matayba oppositifolia & Cuba & HQ333479 & HQ333479 \\
\hline H. natarajanii & MUCL $43745^{\mathrm{T}}$ & Basideocarp of Pisolithus tinctorius & India & HQ333480 & HQ333480 \\
\hline H. zimbabweensis & CBS $691.97^{\mathrm{T}}$ & Unidentified leaf litter & Zimbabwe & HQ333481 & HQ333481 \\
\hline H. variabilis sp. nov. & FMR $17592^{\mathrm{T}}$ & Unidentified dead leaves & Vietnam & LR536989 & LR588212 \\
\hline \multirow[t]{2}{*}{ Microthyrium buxicola } & MFLUCC $15-0212^{\mathrm{T}}$ & Leaves of Buxus sp. & Italy & - & КT306551 \\
\hline & MFLUCC 15-0213 & Leaves of Buxus sp. & Italy & - & КT306552 \\
\hline M. microscopicum & CBS $115976^{\mathrm{T}}$ & - & The Netherlands & - & GU301846 \\
\hline M. propagulensis & IFRD $9037^{\mathrm{T}}$ & Fallen leaves of Castanopsis histrix & China & - & KU948989 \\
\hline Pseudopenidiella piceae & CBS $131453^{\mathrm{T}}$ & Needle litter of Picea abies & Czech Republic & JX069868 & JX069852 \\
\hline P. gallaica & CBS $121796^{\mathrm{T}}$ & Unidentified dead leaves & Spain & LT984842 & LT984843 \\
\hline \multirow[t]{2}{*}{ P. podocarpi } & CBS $146067^{\mathrm{T}}$ & Leaves of Podocarpus latifolius & South Africa & MN562140 & MN567647 \\
\hline & СРС 37094 & Leaves of P. latifolius & South Africa & MN562141 & MN567648 \\
\hline P. vietnamensis sp. nov. & FMR $17593^{\mathrm{T}}$ & Unidentified dead leaves & Vietnam & LR536990 & LR536991 \\
\hline Stomiopeltis betulae & CBS 114420 & Betula sp. & Sweden & GU214701 & GU214701 \\
\hline \multirow[t]{2}{*}{ Tumidispora shoreae } & MFLUCC $12-0409^{\mathrm{T}}$ & Dead leaves of Shorea sp. & Thailand & - & KT314073 \\
\hline & MFLUCC 14-0574 & Dead leaves of Shorea sp. & Thailand & - & KT314074 \\
\hline Venturia catenospora & CBS $447.91^{\mathrm{T}}$ & Leaf spot of Salix triandra & Germany & EU035427 & MH873940 \\
\hline$V$. inaequalis & CBS 476.61 & Fruit of Malus sylvestris & Belgium & EU282478 & GU456336 \\
\hline
\end{tabular}

${ }^{1}$ CBS: culture collection of the Westerdijk Fungal Biodiversity Institute, Utrecht, The Netherlands; CPC: culture collection of Pedro Crous housed at the CBS; IFRD: International Fungal Research and Development Centre Research Institute of Resource Insects, Kunming; FMR: Facultat de Medicina, Universitat Rovira i Virgili, Reus, Spain; MFLUCC: Mae Fah Luang University Culture Collection, Chiang Ria, Thailand; MUCL: Mycothèque de L'Université Catholique de Louvain, Louvain-la-Neuve, Belgium; T and IT: ex-type and ex-isotype strain, respectively. ${ }^{2}$ Sequences newly generated in this study are indicated in bold. 
Sequences of the fungi studied here were deposited in GenBank (Table 1), and the alignment used was deposited in TreeBASE (submission number S25760).

\subsection{Phenotypic Study}

Microscopic characterization of the isolates was carried out on potato carrot agar (PCA; potato $20 \mathrm{~g}$, carrot $20 \mathrm{~g}$, agar $13 \mathrm{~g}$, distilled water $1 \mathrm{~L}$ ) and oatmeal agar (OA; Oatmeal $30 \mathrm{~g}$, agar $13 \mathrm{~g}$, distilled water $1 \mathrm{~L}$ ) after 30 days of incubation to get sporulation. Measurements and descriptions of the structures were taken from the specimens mounted in Shear's solution or lactic acid $(100 \% v / v)$. Photomicrographs were obtained using a Zeiss Axio-Imager M1 light microscope (Zeiss, Oberkochen, Germany) with a DeltaPix Infinity X digital camera.

Macroscopic characterization of the colonies was done on PDA, OA, and PCA after 30 days of incubation at $25^{\circ} \mathrm{C}$ in darkness. Cardinal temperatures for growth were obtained on PDA incubated at $5,15,20,25,30,35,37$, and $40^{\circ} \mathrm{C}$ after 14 days in darkness. The colony colors in descriptions are based on Kornerup and Wanscher [26].

Nomenclatural novelties and descriptions were deposited in MycoBank [27]. Ex-type cultures and holotypes, which were dried cultures, were deposited at the Westerdijk Fungal Biodiversity Institute (CBS, Utrecht, The Netherlands).

\section{Results}

BLAST analyses with LSU and ITS sequences confirmed the morphological identification of FMR 17592 and FMR 17593 at the genus level but revealed a relatively low percentage of identity with respect to other species, suggesting they were novel species of Heliocephala and Pseudopenidiella, respectively. The similarity of LSU sequences between FMR 17592 and other Heliocephala species (i.e., Heliocephala gracilis, Heliocephala zimbabweensis, Heliocephala elegans, and H. natarajanii) ranged from $94.04 \%$ to $96.73 \%$. In the case of FMR 17593 , similarity was $97.68 \%$ to P. podocarpi, $96.24 \%$ to P. piceae, and $95.80 \%$ to Pseudopenidiella gallaica. ITS sequences showed lower percentages of identity, with a maximum of $95.10 \%$ between FMR 17592 and the Heliocephala species mentioned above and of $\leq 89.25 \%$ between FMR 17593 and the species of Pseudopenidiella analyzed. A combined analysis of the two loci (ITS and LSU) revealed the status of these fungi with respect to the other species of Heliocephala and Pseudopenidiella and allied genera of the family Microthyriaceae (Figure 1). The total alignment included 20 sequences and comprised $1501 \mathrm{bp}$, from which $604 \mathrm{bp}$ were variable, $864 \mathrm{bp}$ conserved, and 460 bp phylogenetically informative. FMR 17592 and FMR 17593 were included in the full-supported clades representatives of the genera above mentioned and were genetically and morphologically differentiated from their closest phylogenetic relatives.

Key morphological features that distinguish the accepted species of Heliocephala and Pseudopenidiella, including the new taxa described below, are summarized in Tables 2 and 3. 


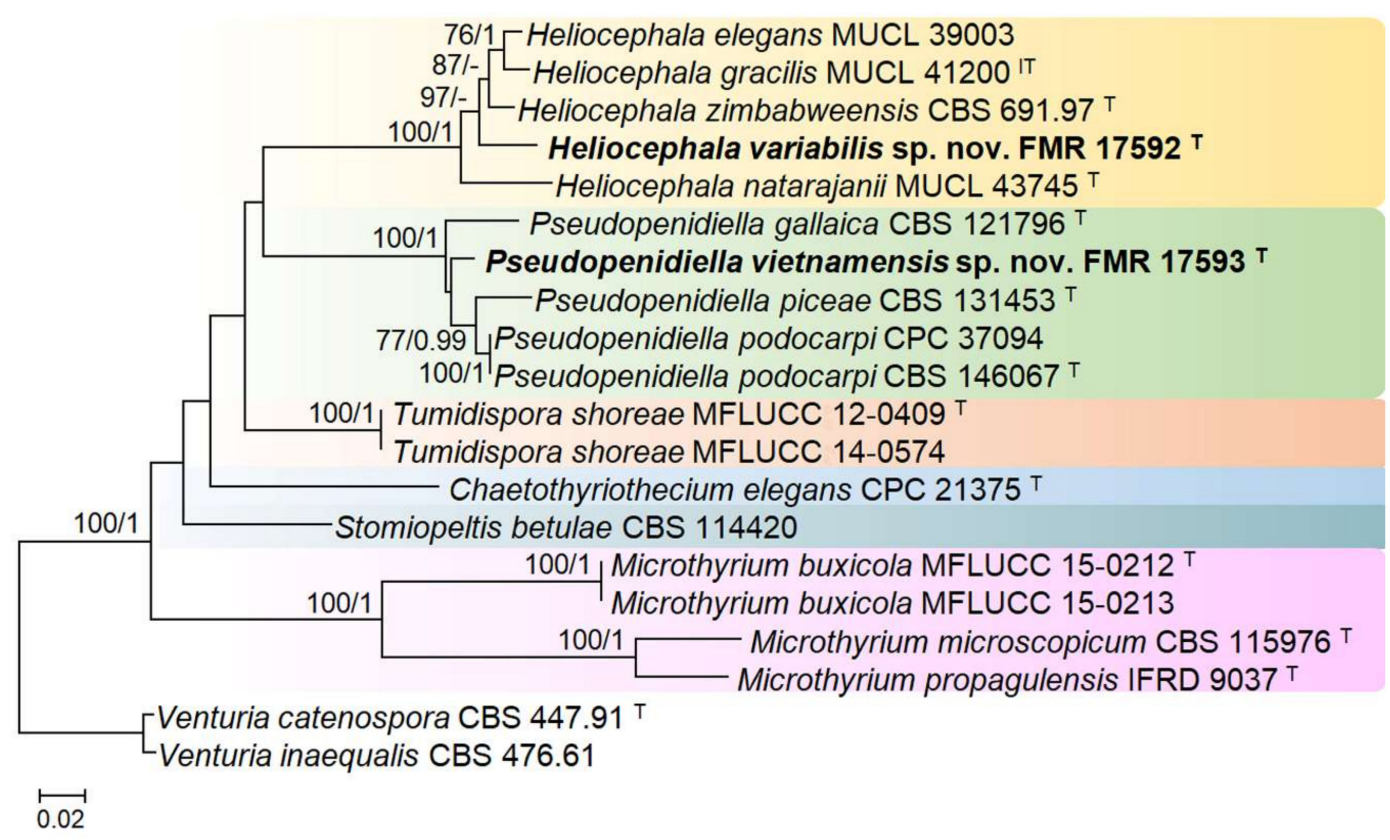

Figure 1. Maximum Likelihood (ML) tree constructed with the internal transcribed spacers (ITS) and large subunit (LSU) sequences of 18 strains representative of the family Microthyriaceae (Microthyriales). The phylogenetic tree was rooted with V. catenospora and V. inaequalis (Venturiaceae, Venturiales). Bootstrap support values for ML greater than $70 \%$ and Bayesian posterior probabilities greater than 0.95 are given near nodes. The names of the newly described species are in bold. Branch lengths are proportional to distance; ${ }^{\mathrm{T}}$ Ex-type strain; ${ }^{\mathrm{IT}}$ Ex-isotype strain. 
Table 2. Key morphological features distinguishing the accepted Heliocephala species.

\begin{tabular}{|c|c|c|c|c|c|c|}
\hline \multirow{2}{*}{ Species } & \multirow{2}{*}{$\begin{array}{l}\text { Conidiophore } \\
\text { Size * }\end{array}$} & \multicolumn{4}{|c|}{ Conidia } & \multirow{2}{*}{ References } \\
\hline & & Size * & Septum No. & Ornamentation & Rostrum & \\
\hline H. elegans & $250-700 \times 7-11$ & $8-25 \times 3-4$ & $1-3$ & Smooth & Present, straight & [10] \\
\hline H. gracilis & $80-350 \times 7-10$ & $4-12.5 \times 2-5$ & $0-1$ & Smooth & Absent & [10] \\
\hline H. natarajanii & up to $109 \times 1.5-3.5$ & $(8.5-) 17-34(-103) \times(1.5-) 2.5-4.5(-6.5)$ & $2(-3)$ & Basal cell verruculose & Present, straight, curved or uncinate & [11] \\
\hline H. proliferans & up to $210 \times 3.5-4$ & $(10-) 15-50(-200) \times 3-4$ & 2 & Basal cell verruculose & Present, straight or curved & {$[8]$} \\
\hline H. triseptata & $21-40 \times 7-19$ & $15-27 \times 3.5-4.5$ & 3 & Smooth & Present, straight & [9] \\
\hline H. variabilis & up to $153 \times 4-6$ & $4-26 \times 3-6$ & $(0-) 1-3(-4)$ & Smooth to verruculose & Absent & Present study \\
\hline H. vietnamensis & $210-340 \times 6-8$ & $14-17 \times 2.8-3.8$ & 3 & Smooth & Absent & [28] \\
\hline H. zimbabweensis & $180-240 \times 3-4$ & $23-125 \times 3.5-5.3$ & 2 & Smooth & Present, straight & [29] \\
\hline
\end{tabular}

Table 3. Key morphological features distinguishing the accepted Pseudopenidiella species.

\begin{tabular}{|c|c|c|c|c|c|c|}
\hline \multirow{2}{*}{ Species } & \multirow{2}{*}{$\begin{array}{l}\text { Macroconidiophore } \\
\text { Size * }\end{array}$} & \multirow{2}{*}{ Microconidiophore } & \multirow{2}{*}{ Ramoconidia Size * } & \multicolumn{2}{|c|}{ Conidia } & \multirow{2}{*}{ References } \\
\hline & & & & Size * & Ornamentation & \\
\hline P. gallaica & up to $120 \times 2-3$ & Present & $7.5-11 \times 2-3$ & $6-12 \times 1-3$ & Smooth to verruculose & [7] \\
\hline P. piceae & up to $150 \times 3-4$ & Present & $8-12 \times 2-3$ & $(6-) 7-9(-10) \times(2.5-) 3$ & Finely verruculose & [12] \\
\hline P. podocarpi & $10-110 \times 3-4$ & Absent & $(9-) 12-13 \times(2.5-) 3-3.5$ & $(9-) 11-12(-15) \times 2.5(-3)$ & Verruculose & [13] \\
\hline P. vietnamensis & up to $236 \times 3-5$ & Absent & $7-13 \times 3-4$ & $5-10 \times 2-3$ & Smooth & Present study \\
\hline
\end{tabular}




\section{Taxonomy}

Heliocephala variabilis Iturrieta-González, Gené, Dania García, sp. nov.-MycoBank MB 833179 (Figure 2).
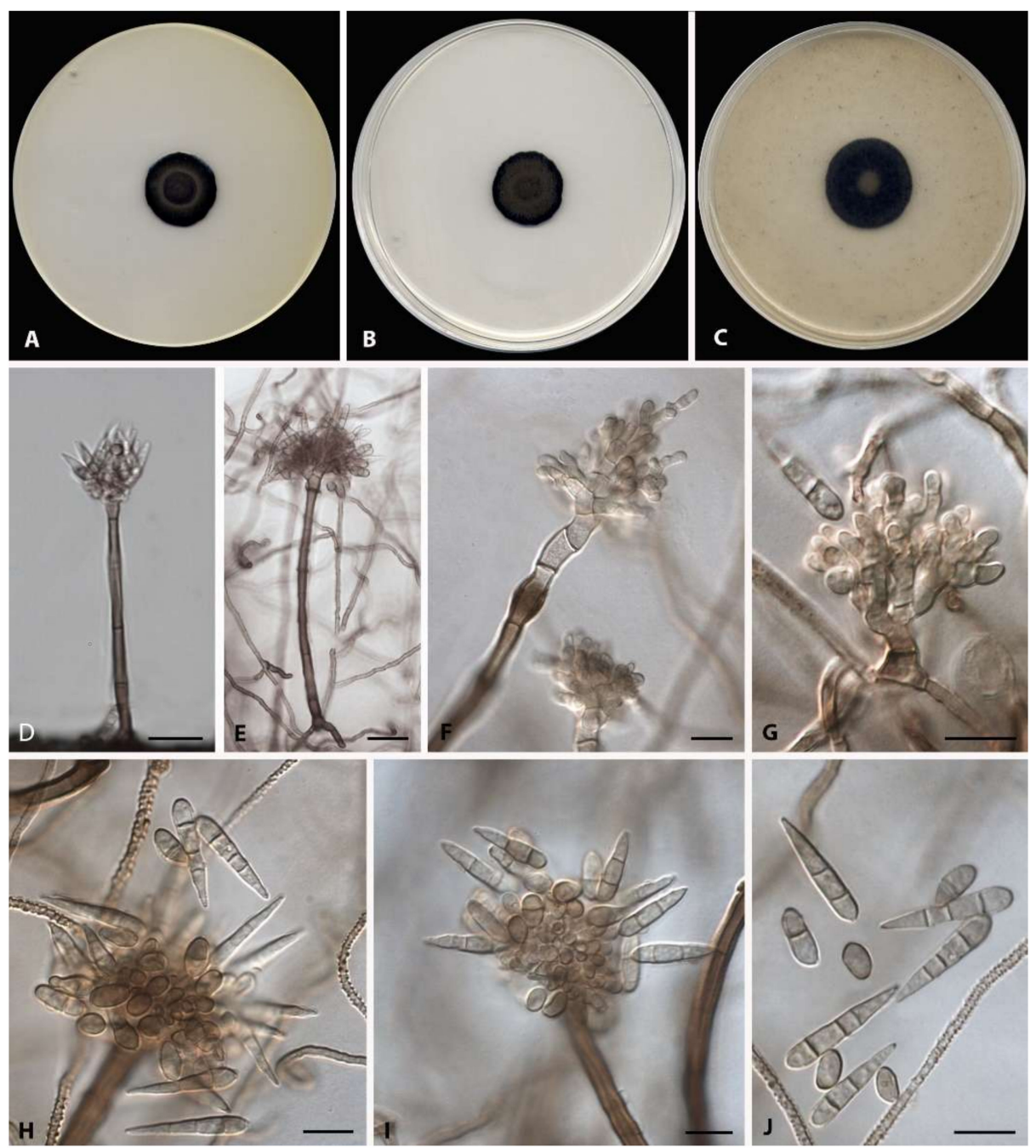

Figure 2. H. variabilis (ex-type FMR 17592). (A-C). Colonies on potato dextrose agar (PDA), potato carrot agar (PCA), and oatmeal agar (OA), respectively, after 30 days at $25^{\circ} \mathrm{C}$. (D-J). Conidiophores and conidia. Scale bars: $(\mathbf{D}, \mathbf{E})=20 \mu \mathrm{m} ;(\mathbf{F}-\mathbf{J})=10 \mu \mathrm{m}$.

Etymology: Name refers to the variation in the conidial morphology.

Mycelium consisting of branched, septate, subhyaline to pale brown, smooth to verrucose hyphae 1-2 $\mu \mathrm{m}$ wide. Conidiophores macronematous, rarely semi-macronematous, mononematous, erect, subcylindrical, with up to seven septa, brown, pale brown towards the apex, smooth-walled, up to $153 \mu \mathrm{m}$ long (up to $148 \mu \mathrm{m}$ long on the natural substratum), 4-6 $\mu \mathrm{m}$ wide, commonly 2-3 closely packed primary branched, from which 1-2 secondary metula-like branches are commonly present. Conidiogenous cells terminal, monoblastic, discrete, ampuliform, smooth-walled, pale brown, 3-13 $\times$ 2-3 $\mu \mathrm{m}$. Conidia solitary, broadly ellipsoidal, subcylindrical or obclavate, smooth-walled to slightly verruculose, pale brown, (0-)1-3-septate (up to 4-septate on the natural substratum): 0-1-septate, 4-11 $\times 3-6 \mu \mathrm{m}$; 2-3-septate 15-26 × 3-5 $\mu \mathrm{m}$; 4-septate 24-26 × 3.8-4.3 $\mu \mathrm{m}$. Sexual morph not observed.

Culture characteristics after 30 days at $25^{\circ} \mathrm{C}$-Colonies on PDA reaching 17-18 mm of diameter, olive color (3F7) with some areas olive-brown (4E4), velvety, convex, aerial mycelium scarce, margin slightly irregular; reverse dark brown (7F8) to black. On PCA, reaching $18 \mathrm{~mm}$ of diameter, yellowish 
brown (5E4), black at the periphery, velvety, flat, aerial mycelium scarce, margin slightly irregular; reverse dark brown (7F8) to black. On OA, reaching $23 \mathrm{~mm}$ of diameter, yellowish brown (5E4), black at the periphery, umbonate, slightly floccose at the center, velvety towards the periphery, margin entire and slightly fimbriate; reverse dark brown (7F8) to black.

Cardinal temperatures for growth: Minimum $15{ }^{\circ} \mathrm{C}$, optimum $25^{\circ} \mathrm{C}$, maximum $30{ }^{\circ} \mathrm{C}$.

Specimen examined: Vietnam, north-east region, on unidentified dead leaf, Aug. 2011, Josep Guarro (holotype CBS H-24291, culture ex-type CBS 146334 = FMR 17592).

Diagnosis: H. variabilis differs from four closely related species, i.e., H. elegans, H. gracilis, H. zimbabweensis, and H. natarajanii, by the size of its macronematous conidiophores and the septation of conidia (Table 2).

Pseudopenidiella vietnamensis Iturrieta-González, Dania García, Gené, sp. nov.-MycoBank MB 833180 (Figure 3).
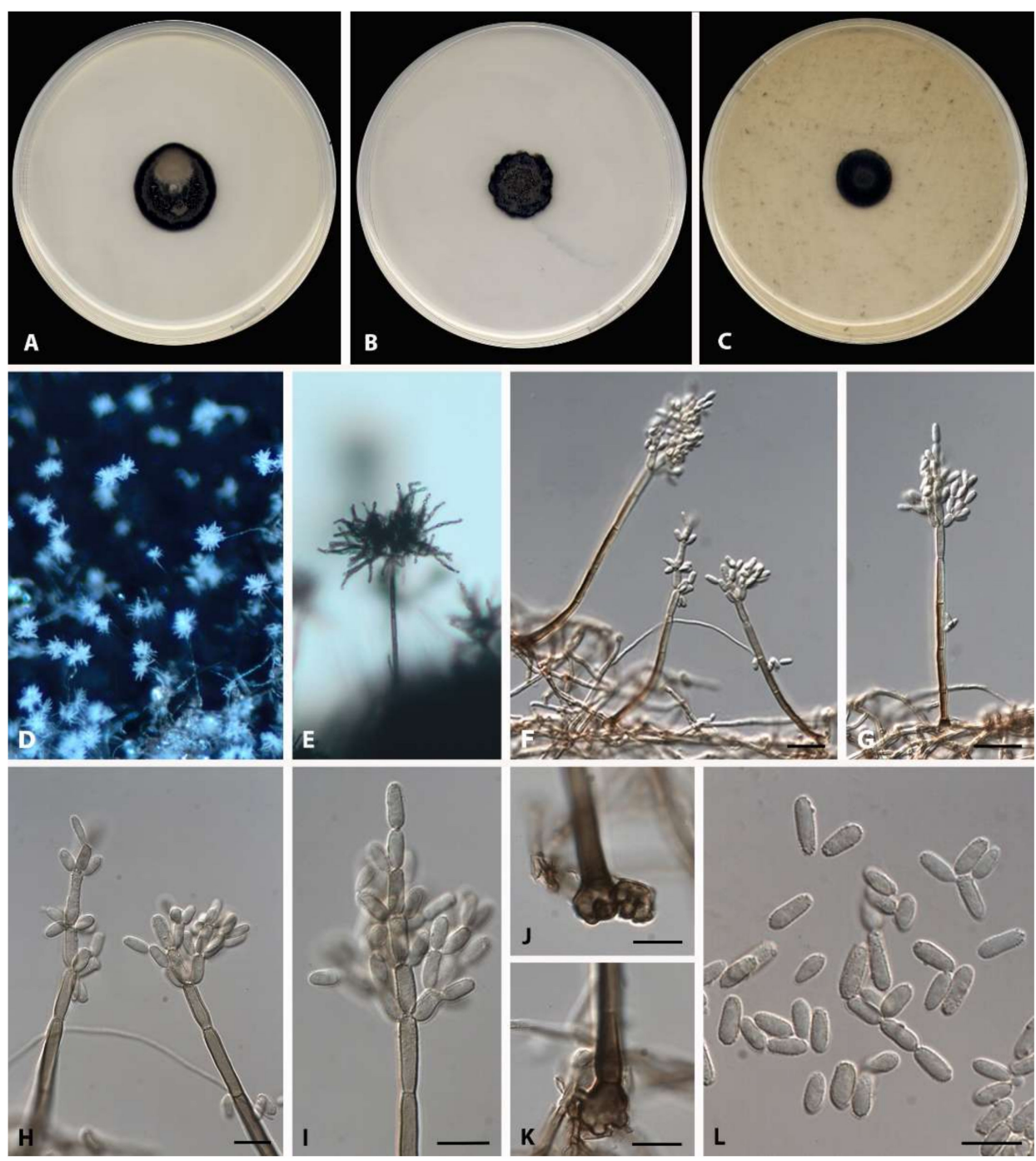

Figure 3. P. vietnamensis (ex-type FMR 17593). (A-C) Colonies on PDA, PCA, and OA, respectively, after 30 days at $25^{\circ} \mathrm{C}$. (D-I,L) Conidiophores and conidia. (D,E) Conidiophores under stereomicroscope. $(\mathrm{J}, \mathbf{K})$ Detail of conidiophore basal cells. Scale bars: $(\mathbf{F}, \mathbf{G})=20 \mu \mathrm{m} ;(\mathbf{H}-\mathbf{L})=10 \mu \mathrm{m}$.

Etymology: Name refers to Vietnam, the country where the fungus was collected.

Mycelium consisting of branched, septate, pale brown, smooth-walled hyphae 1-3 $\mu \mathrm{m}$ wide. Conidiophores macronematous, mononematous, unbranched, erect to slightly flexuous, subcylindrical, with up to 10-septate, pale brown to brown, smooth-walled, verruculose towards the apex, swollen 
and often lobate basal cell, up to $236 \mu \mathrm{m}$ long, 3-5 $\mu \mathrm{m}$ wide; microconidiophores not observed. Conidiogenous cells terminal, polyblastic, with up to three inconspicuous conidiogenous loci, verruculose, pale brown, $12-18 \times 2-4 \mu \mathrm{m}$. Ramoconidia cylindrical, aseptate, pale brown, verruculose, 7-13 $\times 3-4 \mu \mathrm{m}$, forming conidia in acropetal branched chains. Conidia cylindrical, aseptate, pale brown, smooth-walled to verruculose, 5-10 $\times 2-3 \mu \mathrm{m}$. Sexual morph not observed.

Culture characteristics after 30 days at $25^{\circ} \mathrm{C}$ : Colonies on PDA reaching $23 \mathrm{~mm}$ of diameter, grey (7F1) with some regions greyish brown (5D3), black at the edge, velvety, slightly convex, aerial mycelium scarce, margin entire; reverse dark brown (7F8) to black. On PCA, reaching $17 \mathrm{~mm}$ of diameter, brownish grey (5F2), velvety, slightly convex, aerial mycelium scarce, margin undulate; reverse dark brown (7F8) to black. On OA, reaching $15 \mathrm{~mm}$ of diameter, brownish grey (5F2), black at the edge, finely granular, flat, aerial mycelium scarce, margin entire; reverse dark brown (7F6) to black.

Cardinal temperatures for growth: Minimum $15^{\circ} \mathrm{C}$, optimum $25^{\circ} \mathrm{C}$, maximum $30^{\circ} \mathrm{C}$.

Specimen examined: Vietnam, north-east region, on unidentified dead leaf, Aug. 2011, Josep Guarro (holotype CBS H-24292, culture ex-type CBS 146219 = FMR 17593).

Diagnosis: P. vietnamensis differs from P. piceae and P. gallaica in the lack of microconidiophores, and from P. podocarpi in the size of their macronematous conidiophores (Table 3).

\section{Discussion}

Sequence analysis of the ITS and LSU barcodes were enough to resolve the taxonomy of the fungi under study and attribute the species to the monophyletic genera Heliocephala and Pseudopenidiella. However, phylogenetic relationships to other genera in the family Microthyriaceae remained obscure with the present taxon sampling, due to the lack of statistical support in the main clades obtained in the analysis (Figure 1). Despite DNA data not being available for all species of the mentioned genera, the novel species, $H$. variabilis and P. vietnamensis, showed morphological traits that clearly allowed their distinction from the other species of the respective genera (Tables 2 and 3).

Heliocephala variabilis was phylogenetically close to H. elegans, H. gracilis, and H. zimbabweensis. The first two species, which were previously included in the genus Holubovaniella [10], could be differentiated from $H$. variabilis by having much more robust conidiophores (up to $700 \times 11 \mu \mathrm{m}$ in H. elegans; up to $350 \times 10 \mu \mathrm{m}$ in H. gracilis) that usually proliferate, showing several clusters of short branches and intercalary conidiogenous cells. In addition, on the natural substratum, our species showed conidia with up to four septa, while those of H. elegans and H. gracilis are 1-3- and 0-1-septate, respectively [10]. Heliocephala zimbabweensis resembles $H$. proliferans, and both differ from $H$. variabilis by having longer conidiophores (up to $210 \mu \mathrm{m}$ in H. proliferans; up to $240 \mu \mathrm{m}$ in H. zimbabweensis) and two-septate conidia with a very long and filiform rostrum, subsequently showing much longer conidia (10-200 $\mu \mathrm{m}$ in H. proliferans; $23-125 \mu \mathrm{m}$ in H. zimbabweensis) than the species proposed here. Another feature exclusive to $H$. proliferans and $H$. zimbabweensis is the presence of a secondary cluster of conidiogenous cells at the apex of the conidial rostrum [8,29]. The great morphological similarity of these two species suggest they could be conspecific, but the lack of DNA data from the type is a handicap to elucidating the taxonomy of these fungi. Other two Heliocephala species with no molecular data are Heliocephala triseptata and Heliocephala vietnamensis [9,28], but the protologue of both taxa only describes conidia with three septa, and the conidiophores of the former are the smallest ones in the genus (21-40 $\mu \mathrm{m}$ long), while those of $H$. vietnamensis are longer (up to $340 \mu \mathrm{m}$ ) than those observed in H. variabilis (up to $153 \mu \mathrm{m}$ long).

Although the three species of Pseudopenidiella are phylogenetically well differentiated, morphologically they are very similar, and even their conidiogenous apparatus resembles that of other cladosporium-like fungi that belong to the order Capnodiales, such as Penidiella or Apenidiella and other related genera [30,31]. Pseudopenidiella species can be only distinguished by subtle differences in their macroconidiophores and by the presence or absence of microconidiophores, as summarized in Table 3. It is worth mentioning that, based exclusively on morphological data, a fourth species named Pseudopenidiella pini was introduced in the genus by Kirk [32]. This was based on Polyscytalum 
pini, which was described from several specimens collected on decaying needles of Pinus sylvestry, mainly in the United Kingdom. However, none of these specimens is currently available for molecular comparison. Some of the features described and illustrated in its protologue, such as the presence of denticulate conidiogenous cells and one-septate (ramo-) conidia [33], do not fit with the generic concept of Pseudopenidiella [12]; therefore, we prefer to exclude P. pini from the genus until further studies with additional new collections of the species can confirm its position.

Author Contributions: I.I.-G. conceived the ideas, organized and analyzed the data, and joined in the writing; D.G. and J.G. (Josepa Gené) conceived the ideas, analyzed the data, and led the writing; J.G. (Josep Guarro) collected the samples and led the writing. All authors have read and agreed to the published version of the manuscript.

Funding: This study was supported by the Spanish Ministerio de Economía y Competitividad, grant CGL2017-88094-P.

Conflicts of Interest: The authors declare no conflict of interest.

\section{References}

1. Mittermeier, R.A.; Gill, P.R.; Hoffman, M.; Pilgrim, J.; Brooks, T.; Mittermeier, C.G.; Lamoreux, J.; Da Fonseca, G.A.B. Hotspots Revisited: Earths Biologically Richest and Most Endangered Terrestrial Ecoregions; Conservation International: Washington, DC, USA, 2005; p. 392.

2. Sterling, E.J.; Hurley, M.M. Conserving Biodiversity in Vietnam: Applying Biogeography to Conservation Research. Proc. Calif. Acad. Sci. 2005, 56, 98-114.

3. De Queiroz, J.S.; Griswold, D.; Nguyen, D.T.; Hall, P. Vietnam Tropical Forest and Biodiversity Assessment; USAID: Quito, Ecuador, 2013; p. 79.

4. Mel'nik, V.A.; Crous, P.W. Braunomyces dictyosporus gen. sp. nov. from Vietnam. IMA Fungus 2014, 5, 1-5. [CrossRef]

5. Mel'nik, V.A.; Alexandrova, A.V.; Braun, U. Two new species and new records of hyphomycetes from Vietnam. Mycosphere 2014, 5, 591-600. [CrossRef]

6. Brandt, S.C.; Ellinger, B.; van Nguyen, T.; Thi, Q.D.; van Nguyen, G.; Baschien, C.; Yurkov, A.; Hahnke, R.L.; Schäfer, W.; Gand, M. A unique fungal strain collection from Vietnam characterized for high performance degraders of bioecological important biopolymers and lipids. PLoS ONE 2018, 13, e0202695. [CrossRef] [PubMed]

7. Crous, P.W.; Luangsa-ard, J.J.; Wingfield, M.J.; Carnegie, A.J.; Hernández-Restrepo, M.; Lombard, L.; Roux, J.; Barreto, R.W.; Baseia, I.G.; Cano-Lira, J.F.; et al. Fungal Planet description sheets: 785-867. Persoonia 2018, 41, 238-417. [CrossRef] [PubMed]

8. Rao, V.G.; Reddy, K.A.; de Hoog, G.S. Heliocephala, a new genus of dematiaceous Hyphomycetes. Persoonia 1984, 12, 239-242.

9. Heredia-Abarca, G.; Castañeda-Ruiz, R.F.; Arias-Mota, R.M.; Becerra-Hernandez, C.I.; Gómez, S.; Bogale, M.; Untereiner, W.A. A new species of Heliocephala from México with an assessment of the systematic positions of the anamorph genera Heliocephala and Holubovaniella. Mycologia 2011, 103, 631-640. [CrossRef] [PubMed]

10. Castañeda, R.F. Deuteromycotina de Cuba, Hyphomycetes, III; Instituto de Investigaciones Fundamentales en Agricultura Tropical Alejandro de Humboldt: Havana, Cuba, 1985; p. 72.

11. Kumaresan, V.; Srinivasan, M. Heliocephala natarajanii sp. nov. from India. Cryptogam. Mycol. 2002, $23,329-333$.

12. Crous, P.W.; Summerell, B.A.; Shivas, R.G.; Burgess, T.I.; Decock, C.A.; Dreyer, L.L.; Granke, L.L.; Guest, D.I.; Hardy, G.E.S.J.; Hausbeck, M.K.; et al. Fungal Planet Description Sheets: 107-127. Persoonia 2012, 28, $138-182$. [CrossRef] [PubMed]

13. Crous, P.W.; Wingfield, M.J.; Lombard, L.; Roets, F.; Swart, W.J.; Alvarado, P.; Carnegie, A.J.; Moreno, G.; Luangsa-Ard, J.; Thangavel, R.; et al. Fungal Planet description sheets: 951-1041. Persoonia 2019, 43, $223-425$. [CrossRef]

14. Hernández-Restrepo, M.; Silvera-Simón, C.; Mena-Portales, J.; Mercado-Sierra, A.; Guarro, j.; Gené, J. Three new species and a new record of Diplococcium from plant debris in Spain. Mycol. Prog. 2012, 11, 191-199. [CrossRef]

15. Müller, F.M.; Werner, K.E.; Kasai, M.; Francesconi, A.; Chanock, S.J.; Walsh, T.J. Rapid extraction of genomic DNA from medically important yeasts and filamentous fungi by high-speed cell disruption. J. Clin. Microbiol. 1998, 36, 1625-1629. [CrossRef] [PubMed]

16. Cano, J.; Guarro, J.; Gené, J. Molecular and morphological identification of Colletotrichum species of clinical interest. J. Clin. Microbiol. 2004, 42, 2450-2454. [CrossRef] [PubMed] 
17. Crous, P.W.; Schoch, C.L.; Hyde, K.D.; Wood, A.R.; Gueidan, C.; de Hoog, G.S.; Groenewald, J.Z. Phylogenetic lineages in the Capnodiales. Stud. Mycol. 2009, 64, 17-47. [CrossRef] [PubMed]

18. Ariyawansa, H.A.; Hyde, K.D.; Jayasiri, S.C.; Buyck, B.; Chethana, K.W.T.; Dai, D.Q.; Dai, Y.C.; Daranagama, D.A.; Jayawardena, R.S.; Lücking, R.; et al. Fungal diversity notes 111-252-taxonomic and phylogenetic contributions to fungal taxa. Fungal Divers. 2015, 75, 27-274. [CrossRef]

19. Hernández-Restrepo, M.; Gené, J.; Castañeda-Ruiz, R.F.; Mena-Portales, J.; Crous, P.W.; Guarro, J. Phylogeny of saprobic microfungi from Southern Europe. Stud. Mycol. 2017, 86, 53-97. [CrossRef]

20. Marin-Felix, Y.; Groenewald, J.Z.; Cai, L.; Chen, Q.; Marincowitz, S.; Barnes, I.; Bensch, K.; Braun, U.; Camporesi, E.; Damm, U.; et al. Genera of phytopathogenic fungi: GOPHY 1. Stud. Mycol. 2017, 86, 99-216. [CrossRef]

21. Tamura, K.; Stecher, G.; Peterson, D.; Filipski, A.; Kumar, S. MEGA6: Molecular evolutionary genetics analysis version 6.0. Mol. Biol. Evol. 2013, 30, 2725-2729. [CrossRef]

22. Thompson, J.D.; Higgins, D.G.; Gibson, T.J. CLUSTAL W: Improving the sensitivity of progressive multiple sequence alignment through sequence weighting, position-specific gap penalties and weight matrix choice. Nucleic Acids Res. 1994, 22, 4673-4680. [CrossRef]

23. Edgar, R.C. MUSCLE: Multiple sequence alignment with high accuracy and high throughput. Nucleic Acids Res. 2004, 32, 1792-1797. [CrossRef]

24. Ronquist, F.; Teslenko, M.; van der Mark, P.; Ayres, D.L.; Darling, A.; Höhna, S.; Larget, B.; Liu, L.; Suchard, M.A.; Huelsenbeck, J.P. MrBayes 3.2: Efficient Bayesian phylogenetic inference and model choice across a large model space. Syst. Biol. 2012, 61, 539-542. [CrossRef] [PubMed]

25. Posada, D. jModelTest: Phylogenetic Model Averaging. Mol. Biol. Evol. 2008, 25, 1253-1256. [CrossRef] [PubMed]

26. Kornerup, A.; Wanscher, J.H. Methuen Handbook of Colour, 3rd ed.; Methuen Publishing Ltd.: London, UK, 1978; p. 256.

27. Crous, P.W.; Gams, W.; Stalpers, J.A.; Robert, V.; Stegehuis, G. MycoBank: An online initiative to launch mycology into the 21st century. Stud. Mycol. 2004, 50, 19-22.

28. Mel'nik, V.A.; Castañeda-Ruiz, R.F.; Granados, M. A new species of Heliocephala from Vietnam. Mycotaxon 2013, 123, 281-284. [CrossRef]

29. Decock, C.; Robert, V.; Masuka, J.A. Heliocephala zimbabweensis sp. nov. from southern Africa. Mycologia 1998, 90, 330-333. [CrossRef]

30. Crous, P.W.; Braun, U.; Groenewald, J.Z. Mycosphaerella is polyphyletic. Stud. Mycol. 2007, 58, 1-32. [CrossRef]

31. Quaedvlieg, W.; Binder, M.; Groenewald, J.Z.; Summerell, B.A.; Carnegie, A.J.; Burgess, T.I.; Crous, P.W. Introducing the Consolidated Species Concept to resolve species in the Teratosphaeriaceae. Persoonia 2014, 33, 1-40. [CrossRef]

32. Kirk, P.M. Nomenclatural novelties. Index Fungorum 2014, 120, 1.

33. Kirk, P.M. New or interesting microfungi IX. Dematiaceous Hyphomycetes from Esher Common. T. Brit. Mycol. Soc. 1983, 80, 449-467. [CrossRef]

(C) 2020 by the authors. Licensee MDPI, Basel, Switzerland. This article is an open access article distributed under the terms and conditions of the Creative Commons Attribution (CC BY) license (http://creativecommons.org/licenses/by/4.0/). 